 \\ Clinical Research andTherapeutics \\ Mary Ann Liebert, Inc. Fublishers
}

\section{Testosterone Decreases Erythropoietin Stimulating Agent Use in Men on Hemodialysis}

\author{
Sandeep Dhindsa, ${ }^{1, *}$ Varuna Nargunan, ${ }^{2}$ Anand Reddy, ${ }^{3}$ Courtney Clubb, ${ }^{3}$ Adnan Haider, \\ Fausto Cheng, ${ }^{3}$ Vivek H. Prasad, ${ }^{3}$ and Paresh Dandona ${ }^{5}$
}

\begin{abstract}
Objective: Erythropoiesis stimulating agents (ESAs) are required in most of the patients with end-stage renal disease (ESRD) for treatment of anemia. Subnormal testosterone concentrations are very common in men with ESRD. Since testosterone is erythropoietic, testosterone replacement therapy (TRT) has the potential to increase hemoglobin and decrease ESA usage in hypogonadal men with ESRD.

Methods: We reviewed charts of men on hemodialysis with subnormal testosterone concentrations at a dialysis center. The hemoglobin concentrations and ESA doses (adjusted for hemoglobin and body weight) of those who were treated with TRT $(n=10)$ were compared with those who did not receive TRT $(n=10)$.

Results: The average duration of TRT was $18 \pm 2$ weeks. Hemoglobin concentrations increased by $1.2 \pm 1.3 \mathrm{~g} / \mathrm{dL}$ in the treated group but did not change in the untreated group ( $p=0.02$ for comparison between groups). ESA doses decreased by $20 \%$ in the TRT group but did not change in the untreated group ( $p=0.03$ for comparison between groups). Four out of the 10 men in the TRT group were no longer on ESAs by the end of the study, whereas all men in the untreated group continued to require ESAs throughout the study.
\end{abstract}

Conclusion: TRT increases hemoglobin concentrations and reduces the requirement of ESAs in men with subnormal testosterone concentrations on hemodialysis.

Keywords: testosterone; anemia; renal failure; erythropoietin; hemodialysis; hypogonadism

\section{Introduction}

Anemia is present in almost all patients with end-stage renal disease (ESRD). ${ }^{1}$ Currently, $>90 \%$ of ESRD patients are on erythropoiesis stimulating agents (ESAs). ${ }^{2}$ Use of ESAs to correct the severe anemia in these patients improves physiological and clinical parameters and quality of life. Although ESAs are very effective in raising hemoglobin concentrations, studies have shown that higher ESA doses tend to increase all-cause mortality. ${ }^{3}$ ESA therapy is usually started if the hemoglobin is $<10 \mathrm{~g} / \mathrm{dL}$ with the goal of maintain- ing hemoglobin between 10 and $12 \mathrm{~g} / \mathrm{dL}$. Targeting higher hemoglobin levels with ESAs results in an increased risk of cardiovascular events. ${ }^{3}$ In fact, ESAs underwent a label change mandated by FDA in 2011 to reflect that association. ${ }^{4}$ These adverse effects may be directly mediated by the hemodynamic or rheological effects of hemoglobin. However, studies have also shown that higher ESA doses increase all-cause mortality independently of hemoglobin. ${ }^{5}$ It is possible that some patients are exposed to higher doses of ESAs due to "ESA hyporesponsiveness," which may

\footnotetext{
${ }^{1}$ Division of Endocrinology, Diabetes and Metabolism, Saint Louis University, St. Louis, Missouri, USA

${ }^{2}$ Medical Center Hospital ProCare, Endocrinology, Odessa, Texas, USA.

${ }^{3}$ Permian Basin Kidney Center, Odessa, Texas, USA.

${ }^{4}$ Department of Medicine, Section of Endocrinology, West Virginia University, Morgantown, West Virginia, USA.

${ }^{5}$ Division of Endocrinology, Diabetes and Metabolism, State University of New York at Buffalo, Williamsville, New York, USA.

*Address correspondence to: Sandeep Dhindsa, MD, Division of Endocrinology, Diabetes and Metabolism, Saint Louis University, 1402 South Grand Boulevard, Schwitalla Hall, 4th Floor, Room M-412, St. Louis, MO 63104, USA, Email: sandeep.dhindsa@health.slu.edu
}

(C) Sandeep Dhindsa et al., 2020; Published by Mary Ann Liebert, Inc. This Open Access article is distributed under the terms of the Creative Commons License (http://creativecommons.org/licenses/by/4.0), which permits unrestricted use, distribution, and reproduction in any medium, provided the original work is properly cited. 
reflect a higher underlying comorbidity burden. One of the causes of anemia in renal failure as well as hyporesponsiveness to ESAs in men is low testosterone concentrations. ${ }^{6}$

Subnormal testosterone concentrations are very common in men with ESRD..$^{7-12}$ In one study of 239 patients referred to a renal center, the prevalence of subnormal total testosterone concentrations $(<288 \mathrm{ng} / \mathrm{dL}$ or $10 \mathrm{nmol} / \mathrm{L}$ ) was $17 \%, 17 \%, 34 \%, 38 \%$, and $57 \%$ in chronic kidney disease stages $1,2,3,4$, and 5, respectively. ${ }^{9}$ The prevalence is even higher in patients with ESRD and type 2 diabetes. ${ }^{13}$ We have shown that $79 \%$ of diabetic men with ESRD have subnormal free testosterone concentrations $(<5 \mathrm{ng} / \mathrm{dL}$ or $0.174 \mathrm{nmol} / \mathrm{L})$. In comparison, the prevalence of subnormal testosterone concentrations was $37 \%$ in diabetic men with normal estimated glomerular filtration rate $(>60 \mathrm{~mL} /$ $\left.\left[\mathrm{min} \cdot 1.73 \mathrm{~m}^{2}\right]\right) .{ }^{13}$ There is a direct correlation between testosterone concentrations and hemoglobin in men with type 2 diabetes and renal insufficiency. ${ }^{14}$ In men on hemodialysis, testosterone concentrations are inversely related to their ESA doses. ${ }^{6}$ Testosterone replacement therapy (TRT) is well known to increase hemoglobin concentrations in men with and without renal failure. ${ }^{15,16}$ Before the advent of ESAs, androgens had been used to treat anemia in men with renal failure. However, the effect of TRT on hypogonadal men on dialysis and receiving ESA therapy has not been evaluated.

Based on that mentioned, we planned a chart review of patients at our dialysis center who received TRT and analyzed their ESA therapy. We hypothesized that TRT will increase hemoglobin concentrations and reduce the requirement of ESAs in men with ESRD.

\section{Methods}

We reviewed the charts of all men with ESRD who had testosterone concentrations measured between January 2016 and December 2019 at a hemodialysis center (Fig. 1). It has been our clinical practice since 2016 to screen all men with ESRD for hypogonadism. ${ }^{13}$ Those men who have subnormal testosterone are referred to an endocrinologist for further workup and discussion about TRT. For the purposes of this analysis, we included men who (1) were between the ages of 18-80 years, (2) currently receiving ESAs, and (3) not receiving TRT before 2016. Forty-nine men received care at our dialysis center during the study period. We excluded two men because they were already on TRT before joining dialysis at our practice. Two men were excluded because they were not receiving ESAs. Twelve men were not interested in being

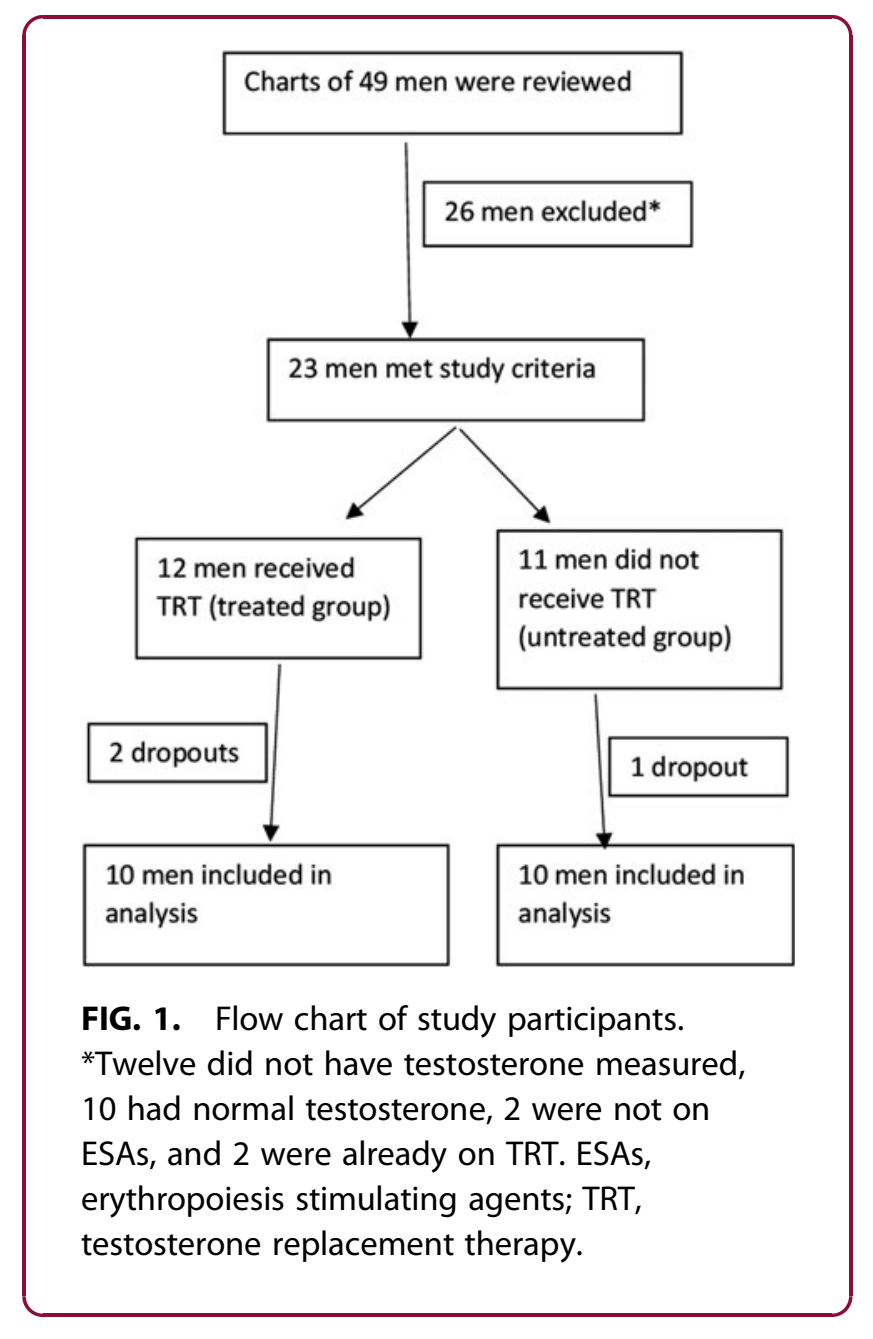

evaluated for low testosterone. Ten men had normal testosterone concentrations, whereas 23 men had subnormal free testosterone ( $<5 \mathrm{ng} / \mathrm{dL} ; 0.174 \mathrm{nmol} / \mathrm{L})$ on two separate occasions. These men were evaluated by an endocrinologist. Ten men had luteinizing hormone (LH) $<10$ IU/L and 12 men had supranormal LH concentrations. None of the patients had severe obstructive sleep apnea, panhypopituitarism, prolactinoma, Klinefelter's syndrome, or congenital causes of hypogonadism. None of the subjects were on opiates or chronic oral steroids. No patients had a history of prostate cancer.

Owing to restrictions of insurance coverage, TRT was prescribed only in the form of intramuscular injections. One man was on warfarin and could not do intramuscular injections. TRT was not started in two men because of elevated prostate specific antigen concentrations. Seven men felt that their symptoms of hypogonadism were not severe enough to try TRT at that time. Thus, 12 men were started on TRT (Fig. 1). 
Treated group

We included men who had received TRT for at least 4 months. We have previously shown that TRT for this duration is sufficient to induce erythropoiesis in men without chronic kidney disease (CKD) ${ }^{15}$ We defined "study period" as starting from 2 months before the initiation of TRT and continuing for at least 4 months on TRT. Subjects who were hospitalized for a medical illness or surgery, received blood transfusion, or had a change in the type of ESAs during the study period were excluded. One man's family complained of his aggressive behavior after 1 month of TRT and his therapy was stopped. Another man underwent coronary artery stent placement after 3 weeks of TRT and did not resume TRT. These two men were excluded from the analysis. Hence, data were available from 10 patients.

TRT was given in the form of intramuscular testosterone cypionate. Therapy was started with $200 \mathrm{mg}$ every 2 weeks. The injections were given during scheduled dialysis sessions by the staff nurses. Serum-free testosterone was measured after 2 months of starting TRT to titrate the dose of testosterone injections, if needed. The blood test was done 1 week after an injection. The dose of TRT was adjusted to maintain free testosterone concentrations in the midnormal range $(10-18 \mathrm{ng} / \mathrm{dL} ; 0.35-0.63 \mathrm{nmol} / \mathrm{L})$ as per endocrine society guidelines. ${ }^{18}$ The dose was increased or decreased in $50 \mathrm{mg}$ per injection increments. The average testosterone dose at the end of the study period was $170 \pm 35 \mathrm{mg}$ every 2 weeks.

The average duration of TRT was $18 \pm 2$ weeks.

\section{Untreated group}

Eleven men did not receive TRT and were used as a comparator group. Study period in these men was defined as 2 months before the measurement of testosterone concentrations and 4 months after that. One man had prolonged hospitalization (for 3 weeks) with pneumonia and respiratory failure during the study period and he was not included in the analysis.

\section{Laboratory measurements}

Blood tests were performed by clinical laboratories as part of standard of care. Total testosterone concentrations (normal range $250-1100 \mathrm{ng} / \mathrm{dL} ; 8.7-38.2 \mathrm{nmol} / \mathrm{L}$ ) were measured by liquid chromatography tandem mass spectrometry (LC-MS/MS). A detailed description of the methodology has previously been published. ${ }^{19}$ The sensitivity of the assay (limit of quantification), set at a coefficient of variation $(\mathrm{CV})$ of $\leq 20 \%$, was
$0.3 \mathrm{ng} / \mathrm{dL}(0.01 \mathrm{nmol} / \mathrm{L})$. The intra-assay $\mathrm{CV}$ ranged from $7.6 \%$ to $10.8 \%$ and interassay $\mathrm{CV}$ ranged from $9.8 \%$ to $13.4 \%$ at total testosterone concentrations between 10 and $1200 \mathrm{ng} / \mathrm{dL}(0.35-41.7 \mathrm{nmol} / \mathrm{L})$. Tracer equilibrium dialysis is considered the gold standard for measuring free steroid hormone concentrations and this methodology was used to determine the free testosterone concentrations (normal range $5-25 \mathrm{ng} / \mathrm{dL}$; $0.174-0.868 \mathrm{nmol} / \mathrm{L}$ ) in our subjects. A detailed description of these methodologies has previously been published. ${ }^{19}$ Total testosterone was measured by LC-MS/ MS and free testosterone was separated by equilibrium dialysis at a commercial laboratory. LH was measured by solid-phase chemiluminescent immunometric assay (IMMULITE 2500; Siemens). Hemoglobin and iron studies were measured by well-established clinical laboratory assays.

\section{Statistical analysis}

The aim of this study was to evaluate the change in hemoglobin concentrations and ESA doses after TRT. We defined the baseline period as 8-week period immediately preceding TRT. End of the study period was defined as the last 8 weeks of follow-up.

Two men in the untreated group were on darbepoetin alfa. One man in the treated group was on methoxy polyethylene glycol-epoetin beta. Rest of the patients were on short-acting epoetin alfa, intravenously three times a week. The direction, magnitude, and frequency of epoetin alfa dose adjustments were determined by the level of hemoglobin and the rate of rise or fall of hemoglobin as per the protocol of the dialysis unit. Hemoglobin was measured every 2 weeks. Epoetin alfa was held if the hemoglobin was $>12 \mathrm{~g} / \mathrm{dL}$. Iron studies (ferritin, iron, and transferrin saturation) were also measured every 4 weeks and iron was replaced intravenously as needed. Iron was replaced weekly unless ferritin was $>200 \mathrm{ng} / \mathrm{mL}$, saturation was $>50 \%$ or hemoglobin was $>13 \mathrm{~g} / \mathrm{dL}$.

The primary end point of the study was to compare the change in ESA dose from baseline after TRT. Doses of epoetin beta and darbepoetin in micrograms were converted to equivalent international units of erythropoietin for purposes of tabulation in the analysis. Typically, a conversion factor of $200-400$ is used, with higher doses requiring a higher conversion factor. ${ }^{20-22}$ We chose a conversion factor of 300 in our study. ESA equivalent dose is presented as $\mathrm{U}$ per week as well as $\mathrm{U} / \mathrm{kg} / \mathrm{Hb} /$ week (adjusted for body weight and hemoglobin) in the following analyses. ESA doses were not normally distributed and were log transformed for 
statistical tests. Secondary end points of the study were to compare the change in hemoglobin concentrations, ferritin, iron, transferrin saturation, and iron replacement after TRT. Data are presented as mean \pm standard deviation for normally distributed data (mean \pm standard error in graphs) and median [25th, 75th percentile] for non-normal data. SPSS software (SPSS, Inc., Chicago, IL) was used for the analyses.

The study protocol was approved by the institutional review board of Saint Louis University.

\section{Results}

Type 2 diabetes was present in $80 \%$ of the men whereas $60 \%$ had coronary artery disease. Data on age, body mass index, testosterone concentrations, hematological parameters, and ESA dose in testosterone treated and untreated groups at baseline and end of study are depicted in Table 1.

Hemoglobin concentrations increased by $1.2 \pm 1.3 \mathrm{~g} / \mathrm{dL}$ in the treated group but did not change in the untreated group $(0.06 \pm 0.48 \mathrm{~g} / \mathrm{dL}, p=0.02$ for comparison between groups). The hemoglobin concentrations appeared to start increasing at week 8 and were significantly higher than baseline by week 16 (Fig. 2). As a response to the increase in hemoglobin, ESA doses decreased in the treated group. The ESA doses (adjusted for body weight and hemoglobin) were lower by $15 \%$ at week 12 and by $30 \%$ at week 16 (Fig. 3). Overall, the ESA doses were lower by $\sim 20 \%$ in the treated group (Table 1 ) but did not change in the untreated group $(p=0.03$ for comparison between groups). The change in ESA was not related to the baseline ESA dose in the testosterone treatment group $(r=-0.19, p=0.58)$.

Four out of the 10 men in the TRT group were no longer on ESAs by the end of the study, whereas all men in untreated group continued to require ESAs throughout the study ( $p=0.09$ for comparison among groups by Fisher Exact probability test). The average baseline hemoglobin concentration was $10.0 \mathrm{~g} / \mathrm{dL}$ in the six subjects in the TRT group who continued to require ESAs during the study, whereas it was $10.9 \mathrm{~g} / \mathrm{dL}$ in the other four subjects who were not on ESAs at the end of the study. Hence the latter four subjects were more likely to reach the threshold hemoglobin concentration of $12 \mathrm{~g} / \mathrm{dL}$, beyond which ESA is held in hemodialysis patients. Those four men also had lower baseline ESA doses (5219 vs. 9550 U/week). They went off ESAs after a mean of 7 weeks and did not require ESAs again during the study period.

Table 1. Demographics, Testosterone Concentrations, Iron Studies, and Erythropoiesis Stimulating Agent Dose in Testosterone Treated and Untreated Groups at Baseline and End of Study

\begin{tabular}{|c|c|c|c|c|c|c|c|}
\hline & \multicolumn{3}{|c|}{ Testosterone $(n=10)$} & \multicolumn{3}{|c|}{ Untreated $(n=10)$} & \multirow{2}{*}{$\begin{array}{c}p \text { for baseline } \\
\text { comparison } \\
\text { between groups* }\end{array}$} \\
\hline & Baseline & End of study & $p$ & Baseline & End of study & $p$ & \\
\hline Age (years) & $59 \pm 9$ & & & $58 \pm 7$ & & & 0.75 \\
\hline $\begin{array}{l}\text { Body mass index } \\
\left(\mathrm{kg} / \mathrm{m}^{2}\right)\end{array}$ & $33.0 \pm 6.0$ & $33.1 \pm 6.3$ & 0.76 & $30.2 \pm 5.6$ & $30.1 \pm 5.4$ & 0.45 & 0.30 \\
\hline Weight $(\mathrm{kg})$ & $92 \pm 16$ & $93 \pm 16$ & 0.88 & $94 \pm 27$ & $94 \pm 27$ & 0.44 & 0.87 \\
\hline $\begin{array}{l}\text { Total testosterone } \\
(\mathrm{ng} / \mathrm{dL} ; \mathrm{nmol} / \mathrm{L})\end{array}$ & $213 \pm 91 ; 7.4 \pm 3.2$ & $771 \pm 194 ; 26.8 \pm 6.7$ & $<0.001$ & $262 \pm 155 ; 9.1 \pm 5.4$ & & & 0.39 \\
\hline $\begin{array}{l}\text { Free testosterone } \\
\quad(\mathrm{ng} / \mathrm{dL} ; \mathrm{nmol} / \mathrm{L})\end{array}$ & $\begin{array}{c}2.8 \pm 1.0 \\
0.097 \pm 0.035\end{array}$ & $\begin{array}{l}11.8 \pm 5.6 \\
0.410 \pm 0.194\end{array}$ & 0.01 & $\begin{array}{c}3.0 \pm 1.3 \\
0.104 \pm 0.045\end{array}$ & & & 0.63 \\
\hline LH (IU/L) & $19 \pm 24$ & & & $15 \pm 13$ & & & 0.69 \\
\hline SHBG (mmol/L) & $51 \pm 32$ & & & $47 \pm 21$ & & & 0.75 \\
\hline Hemoglobin (g/dL) & $10.3 \pm 1.0$ & $11.5 \pm 1.6$ & 0.02 & $10.5 \pm 0.7$ & $10.6 \pm 0.9$ & 0.69 & 0.67 \\
\hline Hematocrit (\%) & $31.0 \pm 2.9$ & $35.0 \pm 4.6$ & 0.01 & $31.5 \pm 2.2$ & $31.7 \pm 2.6$ & 0.69 & 0.72 \\
\hline Ferritin (ng/mL) & $761 \pm 545$ & $794 \pm 363$ & 0.71 & $605 \pm 242$ & $563 \pm 296$ & 0.50 & 0.42 \\
\hline Iron $(\mu \mathrm{g} / \mathrm{dL})$ & $58 \pm 15$ & $47 \pm 18$ & 0.15 & $59 \pm 34$ & $52 \pm 27$ & 0.69 & 0.93 \\
\hline Iron saturation (\%) & $26 \pm 7$ & $26 \pm 11$ & 0.82 & $24 \pm 11$ & $21 \pm 8$ & 0.28 & 0.61 \\
\hline $\mathrm{TIBC}(\mu \mathrm{g} / \mathrm{dL})$ & $239 \pm 39$ & $233 \pm 32$ & 0.52 & $238 \pm 55$ & $244 \pm 51$ & 0.37 & 0.99 \\
\hline UIBC $(\mu \mathrm{g} / \mathrm{dL})$ & $190 \pm 28$ & $191 \pm 25$ & 0.88 & $185 \pm 43$ & $188 \pm 34$ & 0.46 & 0.78 \\
\hline $\begin{array}{l}\text { ESA dose } \\
\text { (U/Kg/Hb/week) }\end{array}$ & $6.05[4.59,11.01]$ & $4.93[0,13.3]$ & 0.04 & $15.80[6.66,42.04]$ & $21.30[5.11,28.87]$ & 0.83 & 0.26 \\
\hline $\begin{array}{l}\text { ESA dose } \\
\text { (U per week) }\end{array}$ & $5300[4438,14,050]$ & $4950[0,15,000]$ & 0.04 & $15,450[6188,30,000]$ & $15,738[4550,30,000]$ & 0.43 & 0.19 \\
\hline $\begin{array}{l}\text { Iron dose } \\
\text { (mg per week) }\end{array}$ & $42 \pm 19$ & $52 \pm 36$ & 0.52 & $69 \pm 50$ & $60 \pm 33$ & 0.60 & 0.13 \\
\hline
\end{tabular}

Within-group comparisons were performed with paired $t$-test. Between-group comparisons for changes were performed by unpaired $t$-tests; ESA doses were log transformed for comparison.

$p<0.05$ is depicted in bold.

ESAs, erythropoiesis stimulating agents; LH, luteinizing hormone; SHBG, sex hormone binding globulin; TIBC, total iron binding capacity; UIBC, unsaturated iron binding capacity. 


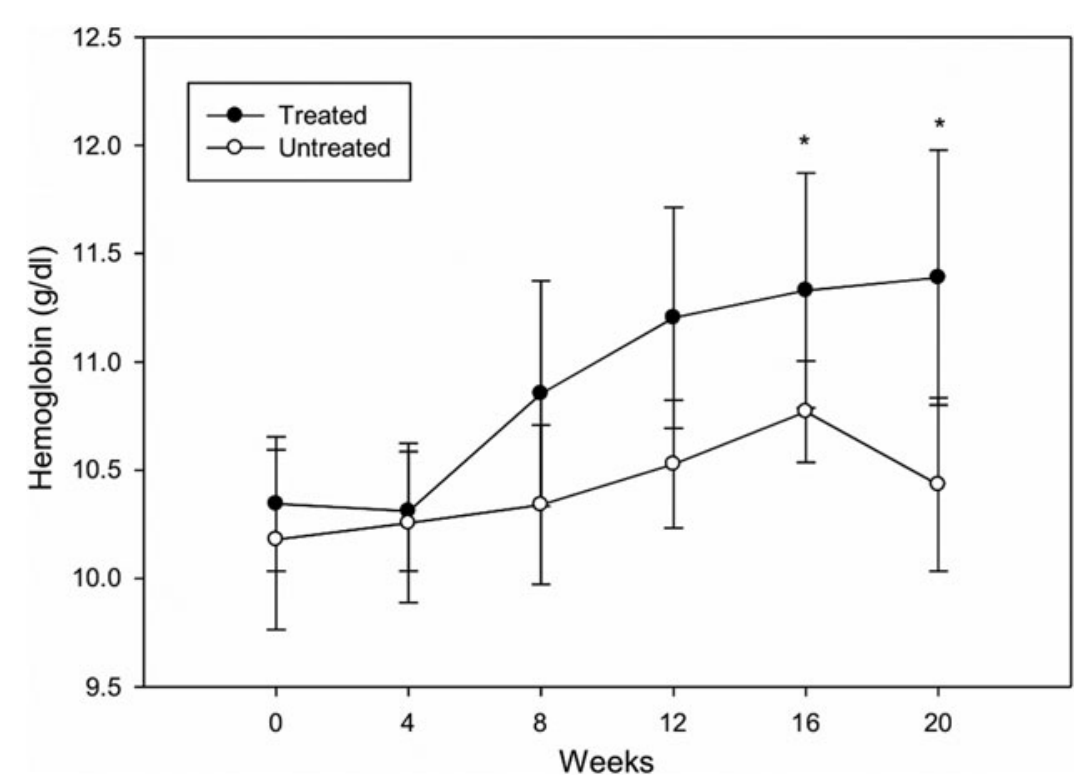

FIG. 2. Hemoglobin concentrations (mean \pm SE) in treated and untreated groups. Hemoglobin concentrations at each time point are an average of the past 4 weeks. For example, week 12 hemoglobin is an average of weeks $9,10,11$, and $12 .{ }^{*} p<0.05$ as compared with 0 weeks. SE, standard error.

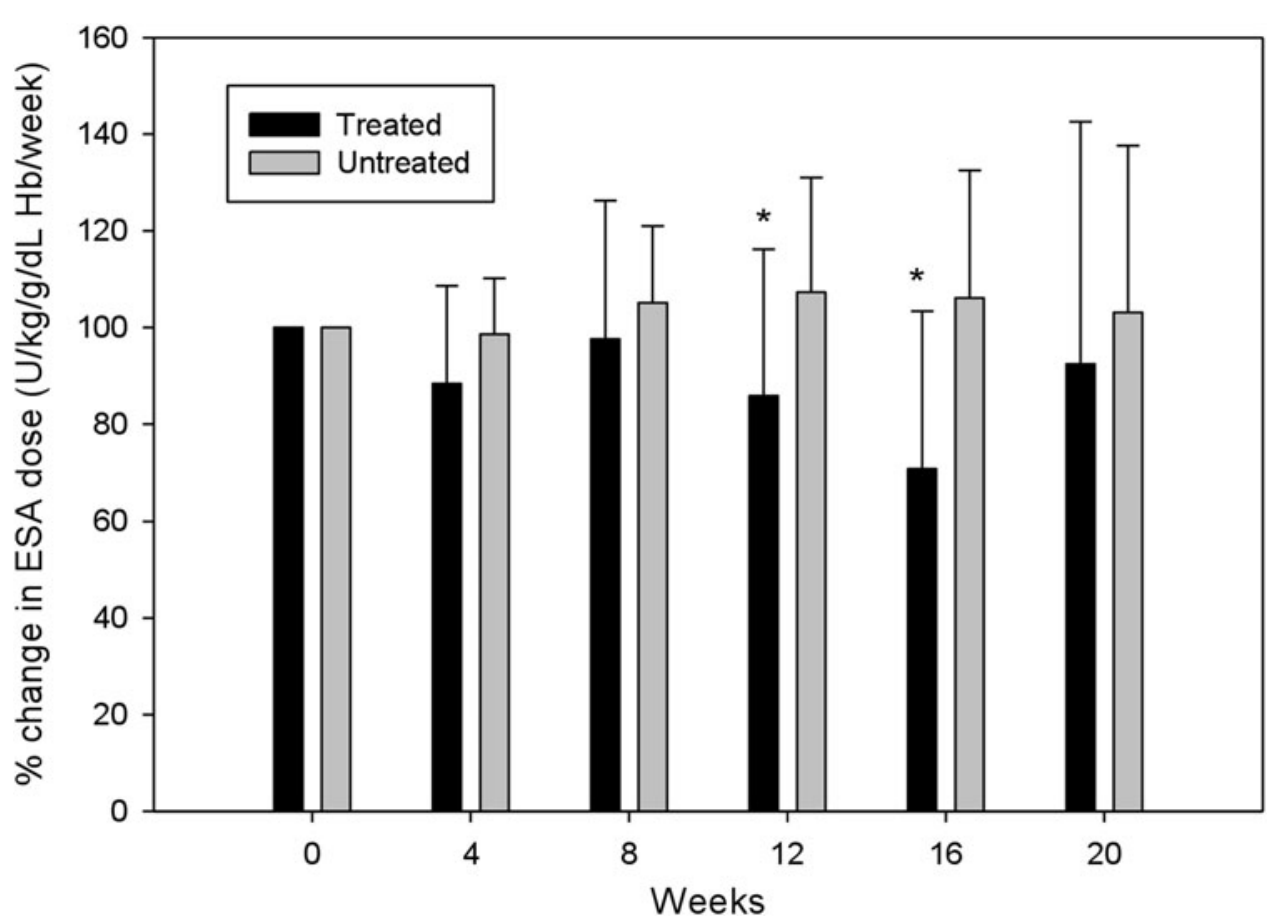

FIG. 3. Percentage change in ESA dose (mean $\pm \mathrm{SE}, \mathrm{U} / \mathrm{Kg} / \mathrm{Hb} /$ week) from baseline (which is depicted as $100 \%$ for both groups). ESA doses at each time point are an average of the past 4 weeks. For example, week 12 ESA dose is an average of weeks $9,10,11$, and $12 .{ }^{*} p<0.05$ as compared with 0 weeks and as compared with the untreated group. 
Follow-up after the study period

In the treated group, only 3 out of 10 are still continuing TRT. One man died due to complications of graft revision surgery, one got a kidney transplant, two men have moved out of town, and three men have been inconsistent with their follow-up with endocrinology for dose titration and prescriptions.

\section{Discussion}

Our data suggest that TRT in hypogonadal men on hemodialysis can decrease requirement of ESAs. This observation is of clinical importance since (1) almost all patients on dialysis therapy are treated with ESAs for anemia and (2) 50-80\% of men with ESRD have subnormal testosterone concentrations. ${ }^{9,13}$ It is remarkable that $40 \%$ of the men were able to stop their ESAs all together due to the improvement in hemoglobin concentrations within 4 months.

A few studies have tried to assess the effect of androgens on erythropoiesis in renal failure. Brockenbrough et al. gave transdermal testosterone to 40 patients who were on hemodialysis and being treated with ESAs. ${ }^{23}$ However, the treatment dose was inadequate and serum testosterone concentrations did not increase significantly. ESA dose also did not change. A study of intramuscular TRT for 6 months in men with hemodialysis showed improved symptoms of hypogonadism but did not change the hemoglobin concentrations. ${ }^{24}$ ESA doses were not analyzed in that study. Testosterone concentrations during the treatment increased from $135 \mathrm{ng} / \mathrm{dL}(4.7 \mathrm{nmol} / \mathrm{L})$ to only $300 \mathrm{ng} / \mathrm{dL}(10.4 \mathrm{nmol} / \mathrm{L}$, low end of normal range). In contrast, the post-treatment testosterone concentrations in our study were $771 \mathrm{ng} / \mathrm{dL}$ $(26.8 \mathrm{nmol} / \mathrm{L})$. Thus, adequate replacement allowed us to detect a change in hemoglobin and ESAs. To the best of our knowledge, there are no other trials with TRT, but a few investigators have studied other androgens (nandrolone and oxymetholone) in addition to ESA treatment. In a randomized placebo controlled trial of oral oxymetholone in combination with ESAs in patients on peritoneal dialysis, hemoglobin and lean body mass in patients improved but significant increases in liver enzymes were also observed. ${ }^{25}$ Intramuscular nandrolone treatment in combination with low dose human recombinant erythropoietin in men on hemodialysis showed an increase in hematocrit by $8 \%$ after $3^{26}$ or 6 months ${ }^{27}$ of treatment. In comparison, the increase in hematocrit was $\sim 3 \%$ in the group who received low dose ESAs without nandrolone. A small study with nandrolone in six patients did not show an increase in hematocrit after nandrolone therapy for 4 months. ${ }^{28}$ Two of those six patients stopped nandrolone due to occurrence of acne. The dose of human recombinant erythropoietin was not adjusted in these studies to achieve a particular hemoglobin target. A Cochrane review in 2014 found a paucity of studies on this topic and insufficient evidence to recommend androgen therapy for improving renal failureassociated anemia. ${ }^{29}$ In view of the large magnitude of the problem and accompanying economic implications, it is surprising that the effect of testosterone on anemia of renal failure has not been investigated systematically. Unlike oral androgens, administration of testosterone by alternative routes (intramuscular and transdermal) does not lead to hepatotoxicity. ${ }^{30}$

The increase in hemoglobin after TRT in our study is similar to the increase noted in men without renal insufficiency. ${ }^{30,31}$ Meta-analyses show that TRT usually increases hemoglobin by $0.8 \mathrm{~g} / \mathrm{dL} .{ }^{16}$ This effect is dose dependent and is evident within a few weeks of starting TRT. ${ }^{32,33}$ Recent studies have shed some light on the mechanisms that underlie testosterone's erythropoietic effect. Testosterone increases erythropoietin and enhances the mobilization of iron from its stores by suppressing hepcidin. This induces an increase in the expression of ferroportin in macrophages. ${ }^{34}$ In the presence of erythropoietin, this translates into increased iron incorporation into red blood cells and erythropoiesis. ${ }^{35,36}$ We have previously shown that TRT in hypogonadal men with type 2 diabetes leads to a significant increase in plasma erythropoietin concentrations, reduction in plasma hepcidin concentration, increase in ferroportin expression, and increase in transferrin receptor in mononuclear cells. ${ }^{15}$ In our study, we did not observe an increase in the dose of iron infusion or a change in ferritin after TRT. Future studies need to investigate whether TRT decreases hepcidin concentrations and increases ferroportin in men with renal failure.

Our study suffers from many limitations inherent in a retrospective study. The two groups were not similar at baseline. Specifically, the median ESA doses were much higher in the untreated group than in the treated group. This is likely due to chance since the hemoglobin levels were similar in the two groups. A major difference in their comorbidities or iron stores was also not apparent. We did not find a relationship between the baseline ESA dose and change in ESAs after testosterone treatment. However, interpretation of such relationship is severely limited due to the small sample size. It is not clear whether testosterone-induced reduction in ESA dose 
would be more or less likely in those with high ESA doses. The short study duration of 4 months is also a significant limitation in our report. It is possible that longer duration of treatment may have a greater magnitude of effect in the reduction of ESA dose and the number of patients requiring ESAs. Nevertheless, we found that the dose of ESAs decreased by $\sim 20 \%$ after TRT for 4 months. This can have significant financial implications for health care of ESRD patients. ESAs are the single largest drug expenditure program in Medicare, with total annual expenditures $>2$ billion dollars for dialysis patients. ${ }^{4}$ The annual average cost per person of ESAs to Medicare is $\sim \$ 6000 .^{37}$ Intramuscular testosterone is generic and costs $\sim \$ 200$ per patient per year. A $20 \%$ reduction in ESA requirements would potentially save $\$ 1000$ per person per year. There are currently 267,000 men in the United States on dialysis. ${ }^{38}$ Conservatively assuming that $60 \%$ of men with ESRD are hypogonadal and that only half of them would get treated, TRT will reduce the annual expenditure on ESAs by $\$ 80$ million. This analysis is an underestimate because it does not include nondialysis CKD 4 and 5 patients who are receiving ESAs. In addition, an increase in hemoglobin can positively impact the clinical state and quality of life. Although we did not collect data on these parameters in this study, these would be important to measure in a prospective trial.

\section{Conclusion}

We conclude that TRT increases hemoglobin concentrations and reduces the requirement of ESAs in hypogonadal men on hemodialysis. These preliminary short-term data need to be confirmed in trials involving a longer duration of therapy and larger number of subjects.

\section{Author Disclosure Statement}

S.D. is a consultant for Bayer and Clarus Therapeutics. P.D. has received research support from National Institutes of Health, JDRF, ADA, Novo Nordisk, Bristol Meyer Squibb, AbbVie Pharmaceuticals, Astra Zeneca, Boehringer Ingelheim Pharmaceuticals, and received honoraria from Eli Lilly, Novartis, GlaxoSmithKline, Merck, Novo Nordisk, Takeda, Sanofi-Aventis. No relevant disclosures are reported for other authors.

\section{Funding Information}

No funding was received for this article.

\section{References}

1. Kazmi WH, Kausz AT, Khan S, et al. Anemia: An early complication of chronic renal insufficiency. Am J Kidney Dis. 2001;38(4):803-812.

2. KDOQI Clinical Practice Guidelines and Clinical Practice Recommendations for Anemia in Chronic Kidney Disease 2006. http:// kidneyfoundation.cachefly.net/professionals/KDOQI/guidelines_anemia/ index.htm (last accessed September 24, 2020).

3. Palmer SC, Navaneethan SD, Craig JC, et al. Meta-analysis: Erythropoiesisstimulating agents in patients with chronic kidney disease. Ann Intern Med. 2010;153(1):23-33.

4. www.fda.gov/Drugs/DrugSafety/ucm259639.htm. 2011.

5. Koulouridis I, Alfayez M, Trikalinos TA, Balk EM, Jaber BL. Dose of erythropoiesis-stimulating agents and adverse outcomes in CKD: A metaregression analysis. Am J Kidney Dis. 2013;61(1):44-56.

6. Carrero JJ, Barany P, Yilmaz MI, et al. Testosterone deficiency is a cause of anaemia and reduced responsiveness to erythropoiesis-stimulating agents in men with chronic kidney disease. Nephrol Dial Transplant. 2012; 27(2):709-715.

7. Handelsman DJ. Hypothalamic-pituitary gonadal dysfunction in renal failure, dialysis and renal transplantation. Endocr Rev. 1985;6(2):151-182.

8. de Vries CP, Gooren LJ, Oe PL. Haemodialysis and testicular function. Int J Androl. 1984;7(2):97-103.

9. Yilmaz MI, Sonmez A, Qureshi AR, et al. Endogenous testosterone, endothelial dysfunction, and cardiovascular events in men with nondialysis chronic kidney disease. Clin J Am Soc Nephrol. 2011;6(7):1617-1625.

10. Khurana KK, Navaneethan SD, Arrigain S, Schold JD, Nally JV, Jr., Shoskes DA. Serum testosterone levels and mortality in men with CKD stages 3-4. Am J Kidney Dis. 2014;64(3):367-374.

11. Bello AK, Stenvinkel P, Lin M, et al. Serum testosterone levels and clinical outcomes in male hemodialysis patients. Am J Kidney Dis. 2014;63(2): 268-275.

12. Carrero JJ, Qureshi AR, Nakashima A, et al. Prevalence and clinical implications of testosterone deficiency in men with end-stage renal disease. Nephrol Dial Transplant. 2011;26(1):184-190.

13. Dhindsa S, Reddy A, Sukhmoy Karam J, et al. Prevalence of subnormal testosterone concentrations in men with type 2 diabetes and chronic kidney disease. Eur J Endocrinol. 2015;173(3):359-366.

14. Grossmann M, Panagiotopolous $S$, Sharpe $K$, et al. Low testosterone and anaemia in men with type 2 diabetes. Clin Endocrinol (Oxf). 2009;70(4): 547-553.

15. Dhindsa S, Ghanim H, Batra M, et al. Effect of testosterone on hepcidin ferroportin, ferritin and iron binding capacity in patients with hypogonadotropic hypogonadism and type 2 diabetes. Clin Endocrinol (Oxf). 2016;85(5):772-780.

16. Fernandez-Balsells $M M$, Murad $M H$, Lane $M$, et al. Clinical review 1 : Adverse effects of testosterone therapy in adult men: A systematic review and meta-analysis. J Clin Endocrinol Metab. 2010;95(6):2560-2575.

17. Dandona P, Dhindsa S. Update: hypogonadotropic hypogonadism in type 2 diabetes and obesity. J Clin Endocrinol Metab. 2011;96:26432651.

18. Bhasin S, Brito JP, Cunningham GR, et al. Testosterone therapy in men with hypogonadism: An Endocrine Society Clinical Practice Guideline. J Clin Endocrinol Metab. 2018;103(5):1715-1744.

19. Salameh WA, Redor-Goldman MM, Clarke NJ, Reitz RE, Caulfield MP. Validation of a total testosterone assay using high-turbulence liquid chromatography tandem mass spectrometry: Total and free testosterone reference ranges. Steroids. 2010;75(2):169-175.

20. Nissenson AR. Dosing darbepoetin alfa. Am J Kidney Dis. 2002;40(4):872.

21. Icardi A, Sacco P, Salvatore F, Romano U. Long-term intravenous epoetinalpha/darbepoetin-alpha ratio in iron-replete hemodialysis patients. J Nephrol. 2007;20(1):73-79.

22. Fliser D, Kleophas W, Dellanna F, et al. Evaluation of maintenance of stable haemoglobin levels in haemodialysis patients converting from epoetin or darbepoetin to monthly intravenous C.E.R.A.: The MIRACEL study. Curr Med Res Opin. 2010;26(5):1083-1089.

23. Brockenbrough AT, Dittrich MO, Page ST, Smith T, Stivelman JC, Bremner WJ. Transdermal androgen therapy to augment EPO in the treatment of anemia of chronic renal disease. Am J Kidney Dis. 2006;47(2):251-262.

24. Inoue $Y$, Nakamura $K$, Kuwahara $Y$, et al. Efficacy of testosterone treatment in hemodialysis patients as assessed by aging males' symptoms scores: A pilot study. Am J Mens Health. 2018;12(5):1541-1547. 
25. Aramwit $P$, Palapinyo $S$, Wiwatniwong $S$, Supasyndh O. The efficacy of oxymetholone in combination with erythropoietin on hematologic parameters and muscle mass in CAPD patients. Int J Clin Pharmacol Ther 2010;48(12):803-813.

26. Ballal SH, Domoto DT, Polack DC, Marciulonis P, Martin KJ. Androgens potentiate the effects of erythropoietin in the treatment of anemia of end-stage renal disease. Am J Kidney Dis. 1991;17(1):29-33.

27. Gaughan WJ, Liss KA, Dunn SR, et al. A 6-month study of low-dose recombinant human erythropoietin alone and in combination with androgens for the treatment of anemia in chronic hemodialysis patients. Am J Kidney Dis. 1997;30(4):495-500.

28. Berns JS, Rudnick MR, Cohen RM. A controlled trial of recombinant human erythropoietin and nandrolone decanoate in the treatment of anemia in patients on chronic hemodialysis. Clin Nephrol. 1992;37(5):264-267.

29. Yang Q, Abudou M, Xie XS, Wu T. Androgens for the anaemia of chronic kidney disease in adults. Cochrane Database Syst Rev. 2014;(10): CD006881.

30. Bhasin S, Cunningham GR, Hayes FJ, et al. Testosterone therapy in men with androgen deficiency syndromes: An Endocrine Society clinical practice guideline. J Clin Endocrinol Metab. 2010;95(6):2536-2559.

31. Shahidi NT. Androgens and erythropoiesis. N Engl J Med. 1973;289(2): 72-80.

32. Beggs LA, Yarrow JF, Conover CF, et al. Testosterone alters iron metabolism and stimulates red blood cell production independently of dihydrotestosterone. Am J Physiol Endocrinol Metab. 2014;307(5):E456-E461.

33. Coviello AD, Kaplan B, Lakshman KM, Chen T, Singh AB, Bhasin S. Effects of graded doses of testosterone on erythropoiesis in healthy young and older men. J Clin Endocrinol Metab. 2008;93(3):914-919.

34. Ganz T. Hepcidin and iron regulation, 10 years later. Blood. 2011;117(17): 4425-4433.

35. Guo W, Bachman E, Li M, et al. Testosterone administration inhibits hepcidin transcription and is associated with increased iron incorporation into red blood cells. Aging Cell. 2013;12(2):280-291.
36. Fried W, Gurney CW. The erythropoietic-stimulating effects of androgens. Ann N Y Acad Sci. 1968;149(1):356-365.

37. U.S. Renal Data System UADRAoCKDaE-SRDitUS, National Institutes of Health, National Institute of Diabetes and Digestive and Kidney Diseases, Bethesda, MD. 2011. https://www.usrds.org/2012/view/v2_11.aspx (last accessed September 24, 2020).

38. United States Renal Data System. 2016 USRDS Annual Data Report: Epidemiology of Kidney Disease in the United States. Bethesda, MD: National Institutes of Health, National Institute of Diabetes and Digestive and Kidney Diseases. 2016.

Cite this article as: Dhindsa S, Nargunan V, Reddy A, Clubb C, Haider A, Cheng F, Prasad VH, Dandona P (2020) Testosterone decreases erythropoietin stimulating agent use in men on hemodialysis, Androgens: Clinical Research and Therapeutics 1.1, 32-39, DOI: 10.1089/andro.2020.0003.

$\begin{aligned} & \text { Abbreviations Used } \\ & \mathrm{CKD}=\text { chronic kidney disease } \\ & \mathrm{CV}=\text { coefficient of variation } \\ & \mathrm{ESAS}=\text { erythropoiesis stimulating agents } \\ & \mathrm{ESRD}=\text { end-stage renal disease } \\ & \mathrm{LC}-\mathrm{MS} / \mathrm{MS}=\text { liquid chromatography tandem mass spectrometry } \\ & \mathrm{LH}=\text { luteinizing hormone } \\ & \mathrm{SE}=\text { standard error } \\ & \mathrm{TRT}=\text { testosterone replacement therapy }\end{aligned}$

Publish in Androgens: Clinical Research and Therapeutics

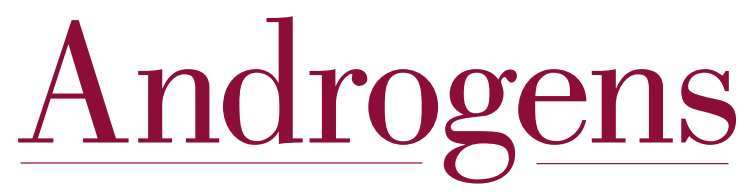

Clinical Research and Therapeutics

liebertpub.com/andro 